\title{
Effect of Continuity of Care on Hospital Utilization for Seniors With Multiple Medical Conditions in an Integrated Health Care System
}

Elizabeth A. Bayliss, MD, MSPH,

Jennifer L. Ellis, MSPH

Jo Ann Shoup, MA ${ }^{1}$

Chan Zeng, $P b D^{1}$

Deanna B. McQuillan, $M A^{1}$

Jobn F. Steiner, $M D, M P H^{1,3}$

'Institute for Health Research, Kaiser Permanente Colorado, Denver, Colorado

${ }^{2}$ Department of Family Medicine, University of Colorado Denver, Aurora, Colorado

${ }^{3}$ Department of Internal Medicine, University of Colorado Denver, Aurora, Colorado

Conflicts of interest: authors report none.

\section{CORRESPONDING AUTHOR}

Elizabeth A. Bayliss, MD, MSPH

Director of Scientific Development

Kaiser Permanente, Institute

for Health Research

Family Medicine

University of Colorado Denver

10065 E Harvard Ave, Ste 300

Denver, CO 80231-5968

elizabeth.bayliss@kp.org

\begin{abstract}
PURPOSE Lower continuity of care has been associated with higher rates of adverse outcomes for persons with multiple chronic medical conditions. It is unclear, however, whether this relationship also exists within integrated systems that offer high levels of informational continuity through shared electronic health records.
\end{abstract}

METHODS We conducted a retrospective cohort study of 12,200 seniors with 3 or more chronic conditions within an integrated delivery system. Continuity of care was calculated using the Continuity of Care Index, which reflects visit concentration with individual clinicians. Using Cox proportional hazards regression permitting continuity to vary monthly until the outcome or censoring event, we separately assessed inpatient admissions and emergency department visits as a function of primary care continuity and specialty care continuity.

RESULTS After adjusting for covariates (demographics; baseline, primary, and specialty care visits; baseline outcomes; and morbidity burden), greater primary care continuity and greater specialty care continuity were each associated with a lower risk of inpatient admission (respective hazard ratios $(95 \% \mathrm{Cls})=0.97(0.96,0.99)$ and $0.95(0.93,0.98))$ and a lower risk of emergency department visits (respective hazard ratios $=0.97(0.96,0.98)$ and $0.98(0.96,1.00))$. For the subgroup with 3 or more primary care and 3 or more specialty care visits, specialty care continuity (but not primary care continuity) was independently associated with a decreased risk of inpatient admissions (hazard ratio $=0.94(0.92,0.97)$ ), and primary care continuity (but not specialty care continuity) was associated with a decreased risk of emergency department visits (hazard ratio $=0.98(0.96,1.00)$ ).

CONCLUSIONS In an integrated delivery system with high informational continuity, greater continuity of care is independently associated with lower hospital utilization for seniors with multiple chronic medical conditions. Different subgroups of patients will benefit from continuity with primary and specialty care clinicians depending on their care needs.

Ann Fam Med 2015;13:123-129. doi: 10.1370/afm.1739.

\section{INTRODUCTION}

$\mathrm{F}$ or older patients with multiple chronic medical conditions (MCCs), greater morbidity is associated with higher rates of hospitalization, emergency service use, and receipt of outpatient care. ${ }^{1-4}$ The older MCC population is also vulnerable to care fragmentation: such patients see more clinicians for both chronic and acute-on-chronic conditions. ${ }^{5,6}$ This care fragmentation is risky as studies of older populations indicate that low continuity of care (COC) is associated with greater inappropriate medication prescribing, higher cost of care, more avoidable hospitalizations, greater use of emergency services, and higher all-cause mortality. ${ }^{7 \cdot 13}$

Several definitions of COC have been developed to capture the separate constructs of information exchange, longitudinal interpersonal relationships, and coordinated care that comprise care continuity. ${ }^{14,15}$ For our purposes, we divide COC into interpersonal COC (the extent to which a 
patient encounters the same clinician for ongoing care) and informational COC (the extent to which clinical information is available to all clinicians participating in a patient's care). ${ }^{16,17}$ Although both constructs have implicit value, it has been difficult to evaluate their separate contributions to health outcomes. Measures that quantify $\mathrm{COC}$ based on proportions of visits to individual clinicians capture interpersonal COC. Complex patients, especially seniors, identify interpersonal continuity as important in maintaining personal relationships with clinicians ${ }^{18,19}$; additionally, higher interpersonal COC is associated with greater patient trust and satisfaction. ${ }^{20-22}$ Studies that have used continuity within sites as a proxy for informational continuity suggest that informational continuity alone can improve medication adherence, and that there is an added benefit from interpersonal COC within sites in obtaining necessary preventive care. ${ }^{23-25}$ Interpersonal COC does not, however, appear to improve cardiovascular risk management in an integrated delivery system. $^{26}$

To provide optimal care for complex patients, it is important to understand the contributions of interpersonal and informational continuity to outcomes. Shared electronic health records within integrated health care systems have increased and standardized informational continuity. In the context of such high and uniform informational continuity, it may be possible to more accurately assess the effect of interpersonal continuity on health outcomes for complex patients.

In this investigation, we assessed the effects of interpersonal COC on rates of hospital utilization in a population of seniors with MCCs in an integrated health care delivery system. We hypothesized that higher interpersonal COC would be associated with lower rates of inpatient admissions and emergency department use in this complex patient population. On the premise that some complex patients may be likely to have meaningful continuity relationships with specialists, we examined both primary and specialty care continuity.

\section{METHODS}

\section{Population}

We conducted a retrospective cohort study that assessed 2 types of hospital utilization (inpatient admissions and emergency department [ED] visits) as a function of morbidity burden and interpersonal continuity of care. The cohort consisted of 12,200 adult members of Kaiser Permanente Colorado (KPCO), a not-forprofit, integrated health care delivery system. Cohort members were aged 65 years or older on January 1 , 2010; had at least 1 year of enrollment before and at least 2 years of enrollment after this date; and had 3 or more of a list of 10 common chronic medical conditions at that time (hypertension, congestive heart failure, hyperlipidemia, diabetes, coronary artery disease, chronic obstructive pulmonary disease, osteoarthritis, osteoporosis, depression, and obesity). We excluded members who had a skilled nursing facility admission in the year before the index date. All KPCO members select a primary care physician, who is listed on their electronic medical record. Members may request this clinician or another when calling for appointments.

\section{Measures}

We defined interpersonal COC using the Continuity of Care Index (COCI) developed by Bice and Boxerman. ${ }^{27}$ This index is suitable for populations having multiple morbidities because it captures the concentration of visits to individual clinicians, is sensitive to the number of clinicians seen, and can be applied in both primary and specialty care. As patients having high levels of morbidity may experience continuity relationships with specialists as well as primary care clinicians, we calculated primary care continuity and specialty care continuity separately. Calculating a stable COCI value requires 3 or more visits; therefore, for each outcome, we required 3 or more outpatient visits to a primary care clinician, a specialty care clinician, or both between the index date of January 1, 2010, and the outcome event to calculate the COCI value. Given that COC can potentially be affected by the occurrence of an outcome event (eg, increased continuity after a hospitalization), we calculated COCI monthly and treated it as a time-varying covariate until censoring by an outcome event or the end of the observation period. Possible COCI values range from 0 to 1 with higher scores indicating greater continuity.

We separately assessed 2 outcomes of interest, the first inpatient admission and the first ED visit during the 2 years after the index date. Our primary independent variables were the 3 types of COC. Morbidity burden was calculated using the Quan adaptation of the Elixhauser comorbidity index. ${ }^{28}$ Covariates included demographic information (age, sex, race/ethnicity, socioeconomic status as calculated from census data), number of baseline primary and specialty care visits, and whether an individual had an outcome event during the year before the index date.

All data were extracted from the electronic health record and hospital claims data.

\section{Analysis}

Using 3 separate Cox regression models for each hospital utilization outcome, we calculated the hazard ratio for each outcome within each of 3 overlapping subcohorts that were defined by having sufficient visits 
to calculate each type of continuity: a subcohort for which members had at least 3 primary care visits; a subcohort for which members had at least 3 specialty care visits; and a subcohort for which members had 3 or more primary care and 3 or more specialty care visits. We then calculated the adjusted hazard ratio for experiencing the outcome event as a function of time-dependent COCI, baseline morbidity burden, and covariates. Individuals who did not experience outcomes were censored at the end of the observation period. We compared characteristics of those included in the analyses with those excluded because of insufficient visits and also compared characteristics of the overlapping populations included in each model.

The study was approved by the KPCO Institutional Review Board.

\section{RESULTS}

The original cohort consisted of 12,200 individuals who were continuously enrolled for 3 years between December 2008 and August 2012. The number of individuals in each COC subcohort (primary care, specialty care, and primary and specialty care) for each outcome depended on the number of visits available for COC calculations before the outcome event for that subgroup (Figure 1).

Characteristics of each continuity subcohort are listed in Table 1. The primary care continuity subcohort had comparable morbidity to, but fewer specialty care visits than, the specialty care continuity subcohort or the overall continuity subcohort. Analyses indicated that $22 \%$ of each subcohort experienced an inpatient admission, and $20 \%$ to $23 \%$ of the subcohorts experienced an ED visit. The mean primary care COCI was 0.6 , indicating relatively little dispersion of care, whereas the mean specialty care COCI of 0.2 reflected substantially more care dispersion.

In bivariate analyses, both primary and specialty continuity were associated with lower risks of inpatient admission and ED use within the relevant

\section{Figure 1. Subcohorts used for analyses of each outcome.}

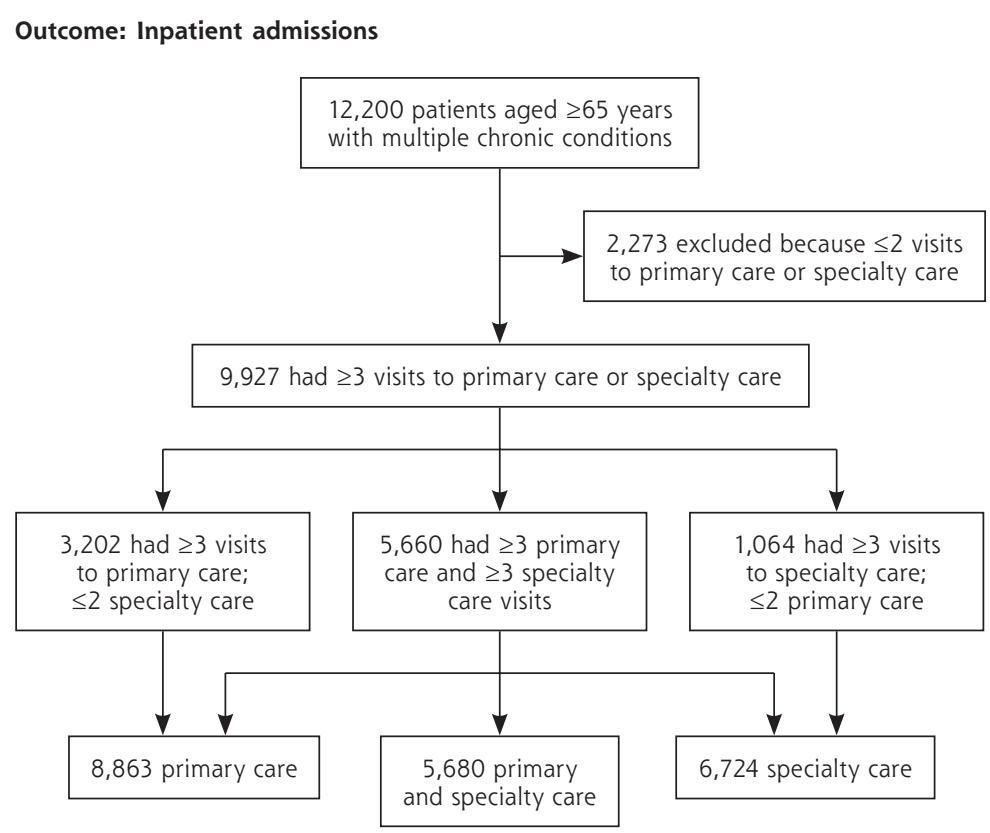

Outcome: Emergency department visits

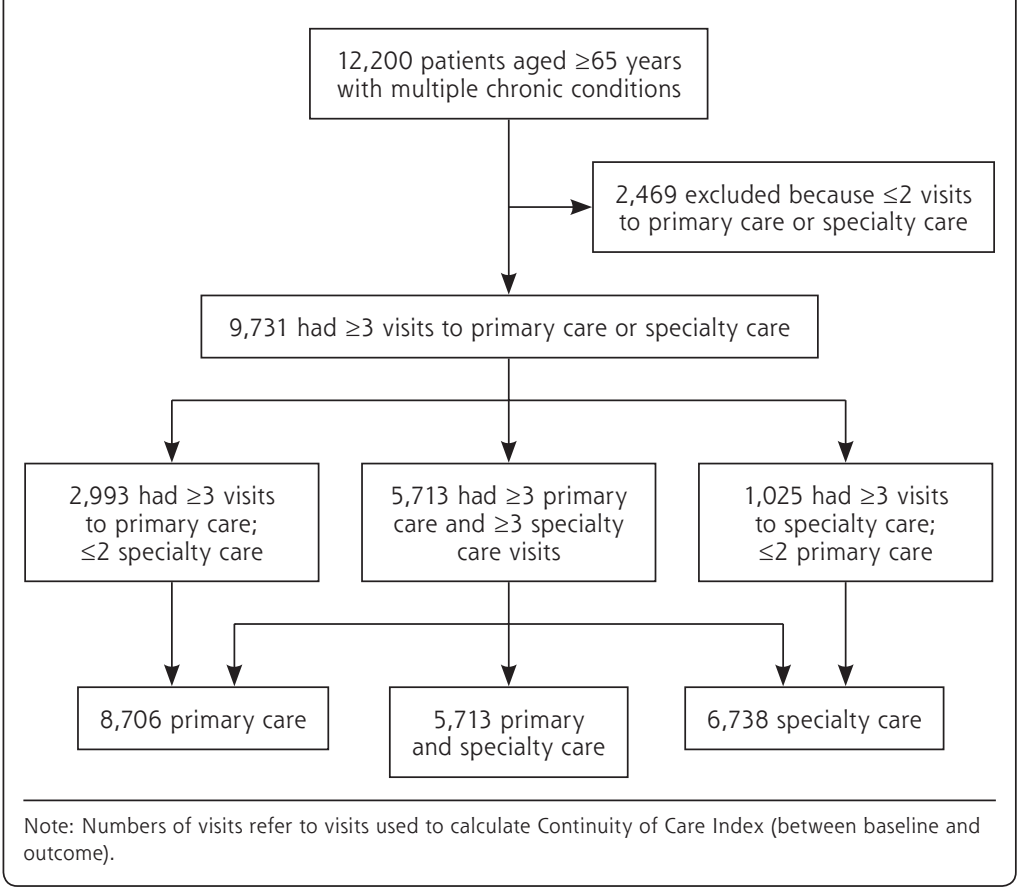

subcohorts (data not shown). In adjusted analyses in the primary and specialty care subcohorts, greater primary care continuity and greater specialty care continuity were each associated with a lower hazard of inpatient admission and a lower hazard of ED visits. For the subgroup of MCC patients with 3 or more primary care and 3 or more specialty care visits, specialty 
Table 1. Characteristics of Analytic Subcohorts for Each Outcome

\begin{tabular}{|c|c|c|c|c|c|c|}
\hline \multirow[b]{2}{*}{ Characteristic } & \multicolumn{3}{|c|}{ Inpatient Admissions } & \multicolumn{3}{|c|}{ Emergency Department Visits } \\
\hline & $\begin{array}{l}\text { Primary Care }^{a} \\
(n=8,863) \\
\text { Mean (SD) }\end{array}$ & $\begin{array}{l}\text { Specialty Care }^{a} \\
(n=6,724) \\
\text { Mean (SD) }\end{array}$ & $\begin{array}{l}\text { Primary and } \\
\text { Specialty Care } \\
(n=5,660) \\
\text { Mean (SD) }\end{array}$ & $\begin{array}{c}\text { Primary Care }^{\mathrm{a}} \\
(\mathrm{n}=\mathbf{8}, 706) \\
\text { Mean (SD) }\end{array}$ & $\begin{array}{l}\text { Specialty Care }^{a} \\
(n=6,738) \\
\text { Mean (SD) }\end{array}$ & $\begin{array}{c}\text { Primary and } \\
\text { Specialty Care } \\
\text { (n=5,713) } \\
\text { Mean (SD) }\end{array}$ \\
\hline Age, y & $76.0(6.0)$ & $75.8(5.9)$ & $76.0(5.9)$ & $75.9(6.0)$ & $75.8(5.8)$ & $76.0(5.8)$ \\
\hline Morbidity burden ${ }^{b}$ & $4.3(2.4)$ & $4.4(2.5)$ & $4.4(2.5)$ & $4.3(2.5)$ & $4.5(2.5)$ & $4.5(2.5)$ \\
\hline \multicolumn{7}{|l|}{ Baseline visits, No. } \\
\hline Primary care & $3.8(2.8)$ & $3.8(2.8)$ & $4.0(2.9)$ & $3.7(2.8)$ & $3.7(2.8)$ & $3.9(2.8)$ \\
\hline Specialty care & $3.2(3.6)$ & $4.1(3.9)$ & $4.1(4.0)$ & $3.3(3.7)$ & $4.1(4.0)$ & $4.1(4.0)$ \\
\hline \multicolumn{7}{|l|}{$\mathrm{COCl}^{\mathrm{c}}$} \\
\hline Primary care & $0.6(0.3)$ & - & $0.6(0.3)$ & $0.6(0.3)$ & - & $0.6(0.3)$ \\
\hline \multirow[t]{2}{*}{ Specialty care } & - & $0.2(0.2)$ & $0.2(0.2)$ & - & $0.2(0.2)$ & $0.2(0.2)$ \\
\hline & Percent & Percent & Percent & Percent & Percent & Percent \\
\hline Female sex & 56.4 & 55.0 & 55.4 & 55.6 & 54.2 & 54.2 \\
\hline \multicolumn{7}{|l|}{ Race/ethnicity } \\
\hline White & 78.8 & 80.8 & 81.0 & 79.1 & 81.1 & 81.2 \\
\hline Black & 4.4 & 4.1 & 4.0 & 4.2 & 3.9 & 3.8 \\
\hline Hispanic & 10.5 & 9.2 & 9.4 & 10.3 & 9.1 & 9.4 \\
\hline Other & 1.8 & 1.7 & 1.6 & 1.8 & 1.7 & 1.7 \\
\hline Unknown & 4.6 & 4.2 & 3.9 & 4.5 & 4.2 & 3.9 \\
\hline Low socioeconomic status & 15.4 & 14.3 & 14.2 & 15.0 & 14.2 & 13.8 \\
\hline \multicolumn{7}{|l|}{ Baseline utilization } \\
\hline Inpatient admissions & 16.9 & 18.7 & 18.7 & - & - & - \\
\hline $\begin{array}{l}\text { Emergency department } \\
\text { visits }\end{array}$ & - & - & - & 17.0 & 17.5 & 17.8 \\
\hline Experienced any outcome ${ }^{d}$ & 21.7 & 22.8 & 20.6 & 22.9 & 23.4 & 20.4 \\
\hline \multicolumn{7}{|l|}{$\mathrm{COCl}=$ Continuity of Care Index. ${ }^{27}$} \\
\hline $\begin{array}{l}\text { a Three visits required for subcol } \\
\text { b According to the Quan-adapted } \\
\text { ' Last measured before outcome } \\
{ }^{d} \text { Hospital admission or emerger }\end{array}$ & $\begin{array}{l}\text { t entry. } \\
\text { ixhauser comorbidit } \\
\text { censoring. Possible } \\
\text { department visit. }\end{array}$ & $\begin{array}{l}\text { index. }{ }^{28} \\
\text { alues range from } 0 t\end{array}$ & ith higher scores ir & ing greater cont & & \\
\hline
\end{tabular}

care continuity, but not primary care continuity, was significantly associated with a decreased risk of inpatient admissions; and primary care, but not specialty care continuity, was independently associated with a decreased hazard of emergency department visits (Tables 2 and 3). For all subcohorts, a higher level of morbidity at baseline was associated with an increased hazard of both outcomes.

Compared with patients excluded from the study because of insufficient visits to calculate the COCI, included patients had slightly higher morbidity (as indicated by the Quan-adapted Elixhauser comorbidity index) and more baseline visits, and were more likely to have experienced each outcome at baseline (data not shown).

\section{DISCUSSION}

In an integrated system with a shared electronic health record that provides informational continuity, measures of interpersonal continuity of care are less likely to serve as proxies for medical knowledge about the patient, and more likely to reflect the benefits of the patient-clinician relationship. Previous studies demonstrating a relationship between greater $\mathrm{COC}$ and lower hospital utilization for patients with MCCs have been conducted with Medicaid, Medicare fee-forservice, and several geographically defined populations in settings where it is not possible to separate these components of continuity. 7,9,29 By demonstrating associations between greater interpersonal COC and lower risk of inpatient or ED admission within an integrated delivery system, our results suggest that interpersonal continuity has a beneficial effect on utilization independent of informational continuity.

Because of the COCI calculation, the absolute effects of increased continuity appear low; however, on a population level, the effects on use of even small increases in continuity may be substantial. For example, based on the information in Table 2, a population of MCC individuals with 3 or more primary care visits would experience a $3 \%$ decrease in the probability of 
Table 2. Effect of Continuity of Care and Morbidity Burden on Adjusted Hazard Ratios of Inpatient Admissions

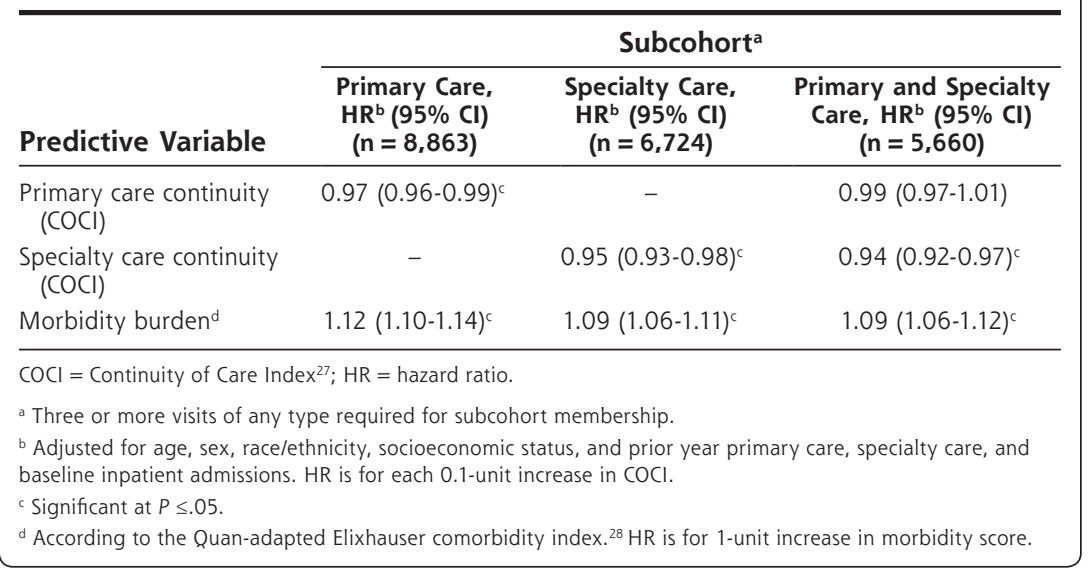

Table 3. Effect of Continuity of Care and Morbidity Burden on Adjusted Hazard Ratios of Emergency Department Visits

\begin{tabular}{|c|c|c|c|}
\hline \multirow[b]{2}{*}{ Predictive Variables } & \multicolumn{3}{|c|}{ Subcohort $^{\mathrm{a}}$} \\
\hline & $\begin{array}{l}\text { Primary Care, } \\
\text { HR }(95 \% \mathrm{Cl})^{\mathrm{b}} \\
(\mathrm{n}=8,706)\end{array}$ & $\begin{array}{l}\text { Specialty Care, } \\
\text { HR }(95 \% \mathrm{Cl})^{\mathrm{b}} \\
\text { (n }=6,738)\end{array}$ & $\begin{array}{l}\text { Primary and Specialty } \\
\text { Care, HR }(95 \% \mathrm{Cl})^{\mathrm{b}} \\
\quad(\mathrm{n}=5,713)\end{array}$ \\
\hline $\begin{array}{l}\text { Primary care continuity } \\
\text { (COCI) }\end{array}$ & $0.97(0.96-0.98)^{c}$ & - & $0.98(0.96-1.00)^{c}$ \\
\hline $\begin{array}{l}\text { Specialty care continuity } \\
\text { (COCI) }\end{array}$ & - & $0.98(0.96-1.00)^{c}$ & $0.98(0.95-1.00)$ \\
\hline Morbidity burden ${ }^{d}$ & $1.06(1.04-1.08)^{c}$ & $1.05(1.03-1.07)^{c}$ & $1.06(1.03-1.08)^{c}$ \\
\hline \multicolumn{4}{|c|}{$\mathrm{COCl}=$ Continuity of Care Index ${ }^{27} ; \mathrm{HR}=$ hazard ratio. } \\
\hline \multicolumn{4}{|c|}{$\begin{array}{l}\text { a Three or more visits of any type required for subcohort membership. } \\
\text { b Adjusted for age, sex, race/ethnicity, socioeconomic status, and prior year primary care, specialty care, and } \\
\text { baseline emergency department visits. HR is for each 0.1-unit increase in COCI. } \\
\text { ' Significant at } P \leq .05 \text {. }\end{array}$} \\
\hline
\end{tabular}

Although continuity with primary care, specialty care, or both is beneficial, the optimal balance between primary and specialty care clinicians in caring for patients with MCCs is unclear. Starfield et al noted that increasing morbidity was associated with more specialty care, but not primary care use-often for diagnoses that could potentially be addressed in primary care settings. ${ }^{5}$ And Medicare feefor-service beneficiaries can see between 3 and 11 unique clinicians ( 1 to 3 primary care clinicians and 2 to 8 specialists) over a 2-year period. ${ }^{32}$ These patterns reflect an undesirable degree of care fragmentation. In contrast, cancer survivors who receive shared care between primary care and oncology clinicians have better management of comorbid conditions and receive more preventive services, and outcomes of cardiac patients after myocardial infarction are better with shared care between cardiology and primary care. ${ }^{33-35}$ Some complex patients report that specialists may know them as well as their primary care clinicians. ${ }^{36}$

Interpersonal COC is particularly valued by older and more

an inpatient admission for every 0.1 -unit increase in primary care $\mathrm{COCI}$ over a 2-year period.

Within the heterogeneous MCC population, at any point in time, there are likely subgroups of patients who use mostly primary care (eg, those having stable multimorbidity), those who may use more episodic or focused specialty care (eg, early cancer survivors), and those who use both (eg, individuals with unstable cardiac disease as well as multiple comorbidities). "Perfect" continuity of care across clinicians for populations having multiple conditions is thus unlikely to be attainable or even desirable. Complex patients will often require consultation from clinicians with different areas of expertise, and very high overall COC may even indicate insufficient access to specialty care. ${ }^{30,31}$ Our findings that primary care and specialty care continuity have separate associations with outcomes in different subcohorts likely reflect the actual care needs of a heterogeneous and complex patient population. complex patients with worse health status. ${ }^{31,36,37}$ Older MCC patients perceive high COC as a foundation for optimal patient-clinician communication and a component of high-quality care, and are more willing than younger, healthier patients to use their own resources to maintain individual continuity relationships. ${ }^{18,19}$ In general, higher $\mathrm{COC}$ is associated with greater patient satisfaction, trust in the clinician, a sense of security and partnership in care, and better clinician-patient communication. ${ }^{21,22,38,39}$ It is unclear how these constructs are manifested in decreasing the risk of hospital utilization-an outcome that may be more immediately meaningful to systems than to patients. Interpersonal COC with a trusted clinician who implicitly incorporates personal knowledge about patients' context and values is likely to foster more shared decision making, be associated with greater patient activation, and promote better disease control—all intermediate outcomes that can lower the risk of hospitalization or ED use. ${ }^{40-42}$ 
New models of team-based care may, by design, slightly decrease interpersonal continuity while attempting to increase informational continuity and improve care coordination. Advocates of these models point out that better care coordination improves utilization outcomes, that there is a valid (if relatively unexplored) construct of team continuity, and that such care models provide new technology-based opportunities for patient-clinician communication. . $^{730,43}$ Evaluations of patient-centered medical home practice transitions have been inconclusive, however. ${ }^{44-47}$ It remains to be seen whether and how new models of care affect relationships that are meaningful to patients as well as outcomes that are important to delivery systems. Our findings suggest that systems should strive to optimize interpersonal COC (with both primary and specialty care clinicians) in designing team-based models of care for complex patients.

Our investigation has several limitations. First, we required 3 or more visits to calculate a valid COCI value. This approach is consistent with the many previous investigations that use the $\mathrm{COCI}_{i}$ therefore, our results are comparable to those in the existing literature. Individuals excluded from the analysis because of insufficient visits had lower morbidity and fewer outcomes, suggesting that this small group had simpler care needs than the analytic cohorts. Second, our findings reflect a patient population with good access to specialty care. In settings with poor access to specialty care, primary care continuity may be particularly important. Third, unmeasured confounding by morbidity burden is particularly relevant in studies of complex patient populations who receive multidimensional care. We incorporated 4 adjustments for morbidity in each of our analyses (the Quan-adapted morbidity index, baseline primary care visits, baseline specialty care visits, and baseline outcome rates) to address this limitation. Fourth, our cohort size did not permit creating subcohorts within each specialty to explore the low overall levels of specialty care COC and to evaluate the effect of COC within different specialties_-doing so will be an important area for further study. Finally, we did not address the question of whether primary or specialty care is being used appropriately, but only continuity of care with individual clinicians.

Our investigation also had several strengths. We measured $\mathrm{COC}$ as a time-varying variable up until the outcome event and thus avoided potential confounding from changes in care patterns that follow a hospital admission or ED visit. This is a substantial strength relative to cross-sectional analyses. In addition, we studied a large, longitudinal cohort that experienced little loss to follow-up. We also explicitly studied complex patients with 3 or more chronic conditions-an expansion on previous investigations of large and more heterogeneous Medicare populations.

In conclusion, interpersonal continuity of care should be optimized for seniors with MCCs, but not with the single goal of improving hospital utilization. Complex patients value relationships with their clinicians, and different subgroups of patients will benefit from continuity with both primary and specialty care clinicians depending on their care needs. It will be important to understand how patients and clinicians conceptualize these continuity relationships within the context of increasingly integrated care delivery settings, and more multidimensional patient-clinician communication.

To read or post commentaries in response to this article, see it online at http://www.annfammed.org/content/13/2/123.

Submitted July 8, 2014; submitted, revised, September 9, 2014; accepted September 19, 2014.

Key words: multimorbidity; comorbidity; continuity of care; utilization; older adults; physician-patient relations

Funding support: This investigation was funded by the Agency for Healthcare Research and Quality (1R01 HS018404-01). Portions of this material were presented at the North American Primary Care Research Group annual meeting, Ottawa, Ontario, Canada, November 10, 2013, and the annual Academy Health Research meeting, June 8, 2014, San Diego, CA.

\section{References}

1. Steiner CA, Friedman B. Hospital utilization, costs, and mortality for adults with multiple chronic conditions, Nationwide Inpatient Sample, 2009. Prev Chronic Dis. 2013;10:E62.

2. Condelius A, Edberg AK, Jakobsson U, Hallberg IR. Hospital admissions among people $65+$ related to multimorbidity, municipal and outpatient care. Arch Gerontol Geriatr. 2008;46(1):41-55.

3. Lehnert T, Heider D, Leicht $H$, et al. Review: health care utilization and costs of elderly persons with multiple chronic conditions. Med Care Res Rev. 2011;68(4):387-420.

4. Wolff JL, Starfield B, Anderson G. Prevalence, expenditures, and complications of multiple chronic conditions in the elderly. Arch Intern Med. 2002;162(20):2269-2276.

5. Starfield B, Lemke KW, Herbert R, Pavlovich WD, Anderson G. Comorbidity and the use of primary care and specialist care in the elderly. Ann Fam Med. 2005;3(3):215-222.

6. Anderson GF, Knickman JR. Changing the chronic care system to meet people's needs. Health Aff (Millwood). 2001;20(6):146-160.

7. Chu HY, Chen CC, Cheng SH. Continuity of care, potentially inappropriate medication, and health care outcomes among the elderly: evidence from a longitudinal analysis in Taiwan. Med Care. 2012;50(11):1002-1009.

8. Cheng SH, Chen CC, Hou YF. A longitudinal examination of continuity of care and avoidable hospitalization: evidence from a universal coverage health care system. Arch Intern Med. 2010;170(18):1671-1677.

9. Nyweide DJ, Anthony DL, Bynum JP, et al. Continuity of care and the risk of preventable hospitalization in older adults. JAMA Intern Med. 2013;173(20):1879-1885. 
10. Wasson JH, Sauvigne AE, Mogielnicki RP, et al. Continuity of outpatient medical care in elderly men. A randomized trial. JAMA. 1984;252(17):2413-2417.

11. Wolinsky FD, Bentler SE, Liu L, et al. Continuity of care with a primary care physician and mortality in older adults. J Gerontol A Biol Sci Med Sci. 2010;65(4):421-428.

12. Leleu $H$, Minvielle E. Relationship between longitudinal continuity of primary care and likelihood of death: analysis of national insurance data. PLoS One. 2013;8(8):e71669.

13. Hussey PS, Schneider EC, Rudin RS, Fox DS, Lai J, Pollack CE. Continuity and the costs of care for chronic disease. JAMA Intern Med. 2014;174(5):742-748.

14. Haggerty JL, Reid RJ, Freeman GK, Starfield BH, Adair CE, McKendry R. Continuity of care: a multidisciplinary review. BMJ. 2003; 327(7425):1219-1221.

15. Saultz JW. Defining and measuring interpersonal continuity of care. Ann Fam Med. 2003;1(3):134-143.

16. Saultz JW, Lochner J. Interpersonal continuity of care and care outcomes: a critical review. Ann Fam Med. 2005;3(2):159-166.

17. Health Quality Ontario. Continuity of care to optimize chronic disease management in the community setting: an evidence-based analysis. Ont Health Technol Assess Ser. 2013;13(6):1-41.

18. Bayliss EA, Edwards AE, Steiner JF, Main DS. Processes of care desired by elderly patients with multimorbidities. Fam Pract. 2008;25(4):287-293.

19. Pereira AG, Pearson SD. Patient attitudes toward continuity of care. Arch Intern Med. 2003;163(8):909-912.

20. Saultz JW, Albedaiwi W. Interpersonal continuity of care and patient satisfaction: a critical review. Ann Fam Med. 2004;2(5):445-451.

21. Mainous AG III, Baker R, Love MM, Gray DP, Gill JM. Continuity of care and trust in one's physician: evidence from primary care in the United States and the United Kingdom. Fam Med. 2001;33(1):22-27.

22. Hjortdahl P, Laerum E. Continuity of care in general practice: effect on patient satisfaction. BMJ. 1992;304(6837):1287-1290.

23. Hong JS, Kang HC. Relationship between continuity of ambulatory care and medication adherence in adult patients with type 2 diabetes in Korea: a longitudinal analysis. Med Care. 2014;52(5):446-453.

24. Doescher MP, Saver BG, Fiscella K, Franks P. Preventive care. J Gen Intern Med. 2004;19(6):632-637.

25. O'Malley AS, Cunningham PJ. Patient experiences with coordination of care: the benefit of continuity and primary care physician as referral source. J Gen Intern Med. 2009;24(2):170-177.

26. Litaker D, Ritter C, Ober S, Aron D. Continuity of care and cardiovascular risk factor management: does care by a single clinician add to informational continuity provided by electronic medical records? Am J Manag Care. 2005;11(11):689-696.

27. Bice TW, Boxerman SB. A quantitative measure of continuity of care. Med Care. 1977;15(4):347-349.

28. Quan $H$, Sundararajan V, Halfon $P$, et al. Coding algorithms for defining comorbidities in ICD-9-CM and ICD-10 administrative data. Med Care. 2005;43(11):1130-1139.

29. Gill JM, Mainous AG III. The role of provider continuity in preventing hospitalizations. Arch Fam Med. 1998;7(4):352-357.
30. Chen LM, Ayanian JZ. Care continuity and care coordination: what counts? JAMA Intern Med. 2014;174(5):749-750.

31. Salisbury C, Sampson F, Ridd M, Montgomery AA. How should continuity of care in primary health care be assessed? Br J Gen Pract. 2009;59(561):e134-e141.

32. Pham HH, Schrag D, O'Malley AS, Wu B, Bach PB. Care patterns in Medicare and their implications for pay for performance. N Engl J Med. 2007;356(11):1130-1139.

33. Snyder CF, Earle CC, Herbert RJ, Neville BA, Blackford AL, Frick KD. Preventive care for colorectal cancer survivors: a 5-year longitudinal study. J Clin Oncol. 2008;26(7):1073-1079.

34. Earle CC, Neville BA. Under use of necessary care among cancer survivors. Cancer. 2004;101(8):1712-1719.

35. Ayanian JZ, Landrum MB, Guadagnoli E, Gaccione P. Specialty of ambulatory care physicians and mortality among elderly patients after myocardial infarction. N Engl J Med. 2002;347(21):1678-1686.

36. Waibel S, Henao D, Aller MB, Vargas I, Vázquez ML. What do we know about patients' perceptions of continuity of care? A metasynthesis of qualitative studies. Int J Qual Health Care. 2012;24(1): 39-48.

37. Nutting PA, Goodwin MA, Flocke SA, Zyzanski SJ, Stange KC. Continuity of primary care: to whom does it matter and when? Ann Fam Med. 2003;1(3):149-155.

38. Haggerty JL, Roberge D, Freeman GK, Beaulieu C. Experienced continuity of care when patients see multiple clinicians: a qualitative metasummary. Ann Fam Med. 2013;11(3):262-271.

39. Katz DA, McCoy K, Sarrazin MV. Does improved continuity of primary care affect clinician-patient communication in VA? J Gen Intern Med. 2014;29(Suppl 2):S682-S688.

40. Wong ST, Peterson S, Black C. Patient activation in primary healthcare: a comparison between healthier individuals and those with a chronic illness. Med Care. 2011;49(5):469-479.

41. Lorig KR, Sobel DS, Stewart AL, et al. Evidence suggesting that a chronic disease self-management program can improve health status while reducing hospitalization: a randomized trial. Med Care. 1999;37(1):5-14.

42. Naik AD, Kallen MA, Walder A, Street RL Jr. Improving hypertension control in diabetes mellitus: the effects of collaborative and proactive health communication. Circulation. 2008;117(11): 1361-1368.

43. Saba GW, Villela TJ, Chen E, Hammer H, Bodenheimer T. The myth of the lone physician: toward a collaborative alternative. Ann Fam Med. 2012;10(2):169-173.

44. Liss DT, Chubak J, Anderson ML, Saunders KW, Tuzzio L, Reid RJ. Patient-reported care coordination: associations with primary care continuity and specialty care use. Ann Fam Med. 2011;9(4):323-329.

45. Friedberg MW, Schneider EC, Rosenthal MB, Volpp KG, Werner RM. Association between participation in a multipayer medical home intervention and changes in quality, utilization, and costs of care. JAMA. 2014;311(8):815-825.

46. Reid RJ, Coleman K, Johnson EA, et al. The Group Health medical home at year two: cost savings, higher patient satisfaction, and less burnout for providers. Health Aff (Millwood). 2010;29(5):835-843.

47. Fisher ES. Building a medical neighborhood for the medical home. N Engl J Med. 2008;359(12):1202-1205. 